\title{
Conhecimento do cirurgião-dentista referente à avaliação de próteses parciais removíveis e à responsabilidade nos passos de sua confecção
}

\section{Dentist's knowledge on quality evaluation of partial removable dentures and the responsibility related to their manufacturing and installation}

\author{
Luiz Francesquini Júnior ${ }^{1}$, Célia Marisa Rizatti-Barbosa², \\ Gláucia Maria Bovi Ambrosano ${ }^{3}$, Eduardo Daruge Júnior ${ }^{4}$, \\ Mário Marques Fernandes ${ }^{5}$, Leonardo Soriano De Mello Santos ${ }^{6}$
}

\begin{abstract}
Francesquini Jr L, Rizatti-Barbosa CM, Ambrosano GMB, Darugue Jr E, Fernandes MM, Santos LSM. Conhecimento do cirurgião-dentista referente à avaliação de próteses parciais removíveis e à responsabilidade nos passos de sua confecção. Saúde, Ética \& Justiça. 2009;14(1):9-16

REsumo: Quando se revisa a literatura nacional, pouco se encontra a respeito do conhecimento do Cirurgião-Dentista (CD) no concernente à responsabilidade na qualidade de Próteses Parciais Removíveis (PPR) instaladas. Em vista desta situação, buscou-se verificar o nível de conhecimento destes profissionais, inicialmente os de Piracicaba, SP, no que se refere à instalação de PPRs e analisar a legislação pertinente sobre o papel de todos os envolvidos com a PPR. Após a efetiva análise estatística por meio do teste de qui quadrado, concluiu-se que os pesquisados possuem conhecimentos precários necessários para o estabelecimento de um bom planejamento, confecção, bem como de uma correta avaliação das próteses parciais removíveis instaladas e proservação das mesmas. A legislação e jurisprudência concernente à responsabilidade pelos serviços prestados no tocante à PPR coloca o Cirurgião-Dentista como o único responsável pelos serviços de diagnóstico, planejamento, execução na cavidade bucal, escolha da cor dos dentes, da cor da resina, do tipo, forma e tamanho dos dentes, instalação, avaliação e proservação, sendo que a maioria dos profissionais não tem conhecimento destes fatos.
\end{abstract}

Descritores: Odontologia legal. Responsabilidade civil. Prótese parcial removível.

1 Especialista, Mestre e Doutor em Odontologia Legal e Deontologia, e Doutor em Clínica Odontológica - Faculdade de Odontologia de Piracicaba-UNICAMP. Professor Colaborador Voluntário da Faculdade de Odontologia de Piracicaba-UNICAMP.

2 Professora Titular Doutora da Área de Prótese Dentária da Faculdade de Odontologia de Piracicaba - UNICAMP.

3 Professora Titular Livre-Docente da Área de Bioestatística da Faculdade de Odontologia de Piracicaba - UNICAMP.

4 Professor Titular de Odontologia Legal e Deontologia na Faculdade de Odontologia de Piracicaba - UNICAMP. Coordenador do Curso de Especialização em Odontologia Legal e Deontologia na Faculdade de Odontologia de Piracicaba-UNICAMP.

${ }^{5}$ Especialista em Prótese Dentária - PUC de Campinas - SP; Aluno do Curso de Especialização em Odontologia Legal e Deontologia da Faculdade de Odontologia de Piracicaba- UNICAMP; Odontólogo do Ministério Público do Estado do Rio Grande do Sul.

6 Especialista em Cirurgia e Traumatologia Buco Maxilo Faciais pela EAP-APCD Piracicaba-SP; Especialista e Mestre em Odontologia Legal e Deontologia FOP-UNICAMP.

Endereço PARA CORRESPondÊNCIA: Leonardo Soriano de Mello Santos. Rua XV de Novembro, 1315 - Apto. 74 - Centro. Piracicaba - SP. CEP 13.419-235. E-mail: leonardosoriano@ hotmail.com. 
Francesquini Jr L, et al. Conhecimento do cirurgião-dentista referente à avaliação de próteses parciais removíveis.

INTRODUÇÃo

S egundo Di Fiori ${ }^{9}$, para se conseguir êxito nas reabilitações com Próteses Parciais Removíveis (PPRs) é necessário se conhecer as características particulares e próprias de cada um dos componentes constituintes da cavidade bucal. Existem alterações anátomo-histológicas nos tecidos fibromucosos e ósseos de suporte que constituem o rebordo residual. Tais alterações se devem ao envelhecimento natural, pela imposição de forças pela PPR, ou situações traumáticas e/ou patológicas.

AS PPRs podem ser classificadas em três tipos básicos: PPR dento-suportada, PPR dento muco suportada e PPR muco dento suportada. As PPRs são indicadas, mediante sua classificação, de acordo com a possibilidade de submissão do rebordo alverolar à incidência de força mastigatória ${ }^{10}$.

Por razões econômicas, sociais e culturais o uso da Prótese Parcial Removível (PPR) foi popularizado, fazendo com que estas próteses fossem indicadas a uma grande quantidade de indivíduos parcialmente desdentados, em que a decisão para a indicação está fundamentada basicamente na avaliação entre os riscos/benefícios da sua utilização bem como no custo envolvido na confecção dessa peça protética ${ }^{10}$.

Em síntese, se não for buscado um equilíbrio entre a musculatura paraprotética e os elementos constituintes da PPR, pode-se gerar uma instabilidade no aparelho protético que será absorvida como forças laterais pelos dentes pilares. Graças a esse relacionamento, até mesmo dentes com implantação óssea e periodontal debilitada podem ser indicados como pilares, favorecendo a estabilização e a manutenção da condição de saúde das estruturas periodontais de sustentação desses elementos ${ }^{9}$.

Para começar um processo de avaliação clínica deve-se inicialmente conhecer quais as funções orais que são auxiliadas por uma PPR bem planejada. Johnson e Stratton ${ }^{13}$ estabeleceram oito itens: a) mastigação; b) fonética, deve-se respeitar a àrea chapeável, e os dentes anteriores devem permitir que as letras línguo dentais sejam corretamente pronunciadas $^{14}$; c) estética, deve proporcionar harmonia à face, deve-se estudar a forma, o tamanho, o posicionamento e a cor dos dentes ${ }^{14}$; d) estabilização de dentes enfraquecidos; e) balanceio muscular no complexo orofacial; f) prevenção de inclinação; g) prevenção de imigração; h) prevenção de extrusão.

Torna-se igualmente importante saber para quais casos as PPRs são indicadas, pois realizar uma PPR em um caso previamente estabelecido de contraindicação é saber antecipadamente que iremos obter um fracasso neste serviço prestado.

Os objetivos da presente pesquisa foram verificar se os Cirurgiões-Dentistas da cidade de PiracicabaSP possuem os conhecimentos necessários para uma correta avaliação das próteses parciais removíveis instaladas e se são capazes de determinar as prováveis causas de fracassos nestes aparelhos, bem como discutir a legislação vigente no tocante à responsabilidade do cirurgião-dentista e equipe, do paciente e do laboratório em relação às fases exigidas para se disponibilizar uma PPR para uso.

\section{Objetivos}

O presente trabalho teve por objetivos: a) avaliar o conhecimento dos Cirurgiões-Dentistas da cidade de Piracicaba-SP sobre planejamento, confecção e avaliação das PPRs instaladas e proservação das mesmas; b) analisar a legislação vigente acerca da responsabilidade de cada um dos profissionais envolvidos na confecção de uma PPR.

\section{Material e métodos}

Inicialmente submeteu-se a presente pesquisa ao Comitê de Ética em Pesquisa da Faculdade de Odontologia de Piracicaba-UNICAMP, sendo protocolada sob o número 071/2001. Assim, verificouse junto à Prefeitura Municipal de Piracicaba-SP o número real de cirurgiões-dentistas devidamente inscritos e verificou-se que havia 407 inscritos nesta autarquia no mês de setembro de 2001.

A consulta foi realizada junto ao total de profissionais inscritos (407), dentro da listagem fornecida, por meio de um questionário acompanhado do termo de Consentimento Livre e Esclarecido. O questionário foi entregue pessoalmente a cada um dos participantes e foi acordado entre ambas as partes a sua devolução uma semana após a entrega, sendo que alguns dos participantes solicitaram um prazo maior para a devolução do mesmo.

O questionário foi dividido em duas partes, sendo que na primeira foram solicitados dados gerais da formação do cirurgião-dentista e na segunda foram 
Francesquini Jr L, et al. Conhecimento do cirurgião-dentista referente à avaliação de próteses parciais removíveis.

realizadas questões relativas ao conhecimento do cirurgião-dentista quanto à correta avaliação das próteses parciais removíveis instaladas, bem como questões que visavam verificar se estes são capazes de determinar as prováveis causas de fracassos nestes aparelhos.

Após a compilação dos dados, estes foram submetidos à análise estatística pelo teste de qui quadrado $(\alpha=0,05)$.

\section{Resultados}

Dos questionários enviados, finda a coleta dos mes-mos, obteve-se um retorno de aproximadamente $31 \%$ (126) de questionários preenchidos.

Tabela 1. Freqüência de distribuição dos fatores avaliados pelo Cirurgião-Dentista para a estética

\begin{tabular}{|c|c|c|}
\hline $\begin{array}{l}\text { Fatores avaliados para } \\
\text { a estética }\end{array}$ & Freqüência & $\begin{array}{c}\text { Porcentagem } \\
(\%)\end{array}$ \\
\hline Linha do sorriso & 05 & 3,97 \\
\hline Cor e forma dos dentes & 20 & 15,87 \\
\hline $\begin{array}{l}\text { Descrição da PPR } \\
\text { fornecida pelo paciente }\end{array}$ & 07 & 5,55 \\
\hline $\begin{array}{l}\text { Descrição da } \\
\text { PPR pelo CD }\end{array}$ & 01 & 0,79 \\
\hline Fonética & 01 & 0,79 \\
\hline $\begin{array}{l}\text { Harmonia e } \\
\text { simetria facial }\end{array}$ & 04 & 3,17 \\
\hline Não responderam & 54 & 42,86 \\
\hline $\begin{array}{l}\text { Harmonia com dentes } \\
\text { remanescentes e guias } \\
\text { incisais }\end{array}$ & 03 & 2,39 \\
\hline $\begin{array}{l}\text { Grampos que não fiquem } \\
\text { muito exposto }\end{array}$ & 12 & 9,53 \\
\hline $\begin{array}{l}\text { Deixa ao arbítrio dos pa- } \\
\text { cientes, pois estética é } \\
\text { muito subjetiva }\end{array}$ & 01 & 0,80 \\
\hline $\begin{array}{l}\text { Mostra a PPR instalada } \\
\text { com o espelho }\end{array}$ & 07 & 5,55 \\
\hline Oclusão e DVO & 05 & 3,97 \\
\hline $\begin{array}{l}\text { Apresenta a PPR com } \\
\text { os dentes em cera para } \\
\text { o paciente }\end{array}$ & 03 & 2,38 \\
\hline $\begin{array}{l}\text { Espontaneidade do } \\
\text { paciente }\end{array}$ & 01 & 0,79 \\
\hline $\begin{array}{l}\text { Boa estética, boa } \\
\text { fonética e boa } \\
\text { mastigação }\end{array}$ & 02 & 1,59 \\
\hline Total & 126 & 100 \\
\hline
\end{tabular}

No tocante à quantificação dos indivíduos pelo gênero, verificou-se que $66 \%$ eram do gênero feminino.

No que diz respeito à avaliação do fator estético, os pesquisados fizeram inúmeros apontamentos, porém predominou a avaliação da cor e forma dos dentes, conforme pode-se verificar na Tabela 1.

$\mathrm{Na}$ avaliação clínica do fator fonético, também foram feitos inúmeros apontamentos e prevaleceu, como fator mais observado, a pronúncia de palavras, conforme se verifica na Tabela 2. Vale ressaltar que a avaliação do fator fonético por parte do cirurgiãodentista, responsável pela confecção do aparelho protético, é uma atribuição legal prevista na Lei 5.081 de 24 de agosto de 1966, que, em seu artigo $6^{\circ}$, §1, estabelece que compete ao cirurgião-dentista praticar todos os atos pertinentes à Odontologia, decorrentes de conhecimentos adquiridos em curso regular ou em curso de pós graduação, considerando que este tipo de noções e preparação fazem parte da grade curricular das disciplinas de prótese total, prótese fixa e prótese parcial removível, incluindo a inter-relação dos aparelhos protéticos com a musculatura adjacente ${ }^{5}$.

Para o fator mastigatório, foram feitos inúmeros apontamentos e prevaleceu como fator mais

Tabela 2. Freqüência de distribuição dos fatores avaliados pelo Cirurgião-Dentista para a fonética

\begin{tabular}{l|c|c}
\hline $\begin{array}{l}\text { Fatores avaliados } \\
\text { para fonética }\end{array}$ & Freqüência & $\begin{array}{c}\text { Porcentagem } \\
\text { (\%) }\end{array}$ \\
\hline $\begin{array}{l}\text { Pronúncia de palavras } \\
\text { simbilantes }\end{array}$ & 09 & 7,15 \\
Pronúncia de palavras & 16 & 12,70 \\
Mastigação de alimentos & 01 & 0,79 \\
$\begin{array}{l}\text { Adaptação após } \\
\text { 48 horas }\end{array}$ & 01 & 0,79 \\
$\begin{array}{l}\text { Adaptação após } \\
\text { uma semana }\end{array}$ & 01 & 0,79 \\
$\begin{array}{l}\text { Espontaneidade } \\
\text { Presença de chiados }\end{array}$ & 01 & 0,79 \\
$\begin{array}{l}\text { Percepção do paciente } \\
\text { sobre o assunto }\end{array}$ & 01 & 1,59 \\
$\begin{array}{l}\text { Necessidade de encami- } \\
\text { nhar para Fonoaudiólogo }\end{array}$ & 01 & 0,79 \\
$\begin{array}{l}\text { Satisfação do paciente } \\
\text { com a própria pronuncia }\end{array}$ & 01 & 0,79 \\
Outras respostas & 05 & 3,98 \\
Não responderam & 87 & 69,05 \\
\hline Total & 126 & 100 \\
\hline
\end{tabular}


Francesquini Jr L, et al. Conhecimento do cirurgião-dentista referente à avaliação de próteses parciais removíveis.

observado a análise da oclusão, conforme pode-se verificar na Tabela 3.

Tabela 3. Freqüência de distribuição dos fatores avaliados pelo Cirurgião-Dentista para a mastigação

\begin{tabular}{l|c|c}
\hline $\begin{array}{l}\text { Fatores avaliados para } \\
\text { a mastigação }\end{array}$ & Freqüência & $\begin{array}{c}\text { Porcentagem } \\
\text { (\%) }\end{array}$ \\
\hline $\begin{array}{l}\text { Oclusão } \\
\text { Se provoca } \\
\text { dor na ATM e } \\
\text { músculos } \\
\text { Questiona o } \\
\text { paciente sobre } \\
\text { o conforto mastigatório }\end{array}$ & 17 & 13,49 \\
$\begin{array}{l}\text { Espera } \\
\text { informação do } \\
\text { paciente }\end{array}$ & 02 & 1,59 \\
$\begin{array}{l}\text { Pede para o } \\
\text { paciente morder } \\
\text { o cabo do espelho }\end{array}$ & 03 & 8,73 \\
$\begin{array}{l}\text { Quando o paciente } \\
\text { consegue comer } \\
\text { o que não comia }\end{array}$ & 05 & 3,38 \\
$\begin{array}{l}\text { Na proservação } \\
\text { da PPR }\end{array}$ & 01 & 0,79 \\
$\begin{array}{l}\text { Após 48 horas realiza } \\
\text { a avaliação } \\
\text { Após uma semana }\end{array}$ & 01 & 0,79 \\
$\begin{array}{l}\text { Verifica se a } \\
\text { PPR não se desloca } \\
\text { durante a mastigação } \\
\text { Não respondeu }\end{array}$ & 01 & 0,79 \\
\hline Total & 126 & 100 \\
\hline
\end{tabular}

Perguntados se consideravam-se aptos para avaliar PPRs instaladas, verificou-se que $59 \%$ dos CDs responderam que sim.

Quanto à avaliação do grau de satisfação dos pacientes no tocante às PPRs instaladas, verificouse que $60 \%$ afirmaram que estão aptos a fazê-la.

Sobre qual atitude tomariam se o paciente se encontrasse insatisfeito, com a PPRs instalada, verificou-se que $46 \%$ dos CDs fariam outra sem ônus para o paciente, 35\% com ônus e 19\% não a fariam novamente.

Perguntou-se dos CDs se eles removeriam a PPR instalada no caso de o paciente deixar de pagar. Verificou-se que $56 \%$ não o fariam, porém, $44 \%$ alegaram que removeriam a PPR.

Quando perguntados sobre a quem pertence o Prontuário Odontológico, $51 \%$ dos CDs afirmaram pertencer ao paciente, conforme observado no Gráfico 1. O paciente tem por direito, de acordo com a Lei Estadual de São Paulo 10.241, de 17 de março de $1999^{4}$, acesso ao prontuário em qualquer momento do tratamento, nos termos do artigo $3^{\circ}$ da Lei Complementar № 791 de 09 de março de 1995. Alguns pesquisadores, como França ${ }^{11}$, defendem a entrega da documentação aos pacientes no final do tratamento, visto que, como a ficha clínica faz parte do tratamento em si, este contratado e pago, a mesma seria de posse do paciente por este ter pago o tratamento completo, incluindo sua ficha clínica. A autora ressalta ainda que a atitude da entrega da documentação ao final do tratamento demonstra segurança por parte do profissional.

Gráfico 1. Distribuição das respostas dos cirurgiõesdentistas à questão "a quem pertence o prontuário?"

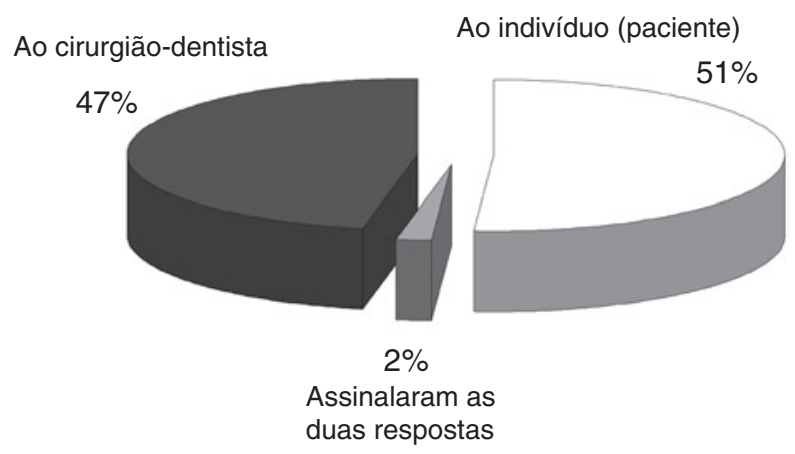

Questionada a freqüência com que os cirurgiõesdentistas participavam de cursos, palestras, aulas, entre outros, verificou-se que $57 \%$ declararam não participar dessas atividades, conforme o Gráfico 2. Esta informação vai de encontro com o estabelecido pelo código de ética odontológico, artigo 5, parágrafo IV, que estabelece a obrigatoriedade da atualização de conhecimentos profissionais, técnico-científicos e culturais para o pleno exercício da profissão ${ }^{3}$.

Questionou-se o Cirurgião-Dentista a respeito da realização de curso sobre PPR e foi constatado que $84 \%$ deles somente o fez durante a graduação.

$\mathrm{Na}$ questão referente a sentir a necessidade de um curso de atualização sobre PPR, $70 \%$ afirmou que sentia tal necessidade.

Foi perguntado também aos cirurgiões-dentistas se eles conhecem o Código de Ética Odontológica e $61 \%$ declarou não ter conhecimento do mesmo.

Relativo ao conhecimento da redação do Código de Ética Odontológica, a respeito das atividades do Técnico de Prótese Dentária e do Auxiliar de Prótese 
Francesquini Jr L, et al. Conhecimento do cirurgião-dentista referente à avaliação de próteses parciais removíveis.

Dentária, verificou-se que $90 \%$ não dispõe de tal conhecimento.

O conhecimento da redação da Resolução 209/97, no que concerne às atividades do Técnico de Prótese Dentária e Auxiliar de Prótese Dentária (ratificada pela resolução 63/2005), verificou-se que $93 \%$ dos profissionais não a conheciam.

Gráfico 2. Distribuição da freqüência de participação em Cursos, palestras, aulas, etc.

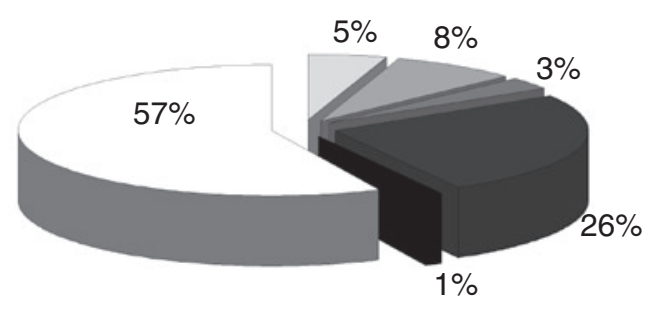

Uma vez por semestre (5\%)

Uma vez a cada ano (8\%)

Uma vez a cada dois anos (3\%)

Sem a periodicidade anterior $(26 \%)$

Assinalou "não participa" e "sem a periodicidade anterior" (1\%) $\square$ Não participa (57\%)

\section{Dıscussão}

A legislação e jurisprudência concernente à responsabilidade pelos serviços prestados no tocante à PPR coloca o Cirurgião-Dentista como o único responsável pelos serviços de diagnóstico, planejamento, execução na cavidade bucal, escolha da cor dos dentes, da cor da resina, do tipo, forma e tamanho dos dentes, instalação, avaliação e proservação.

Analisando-se os dados obtidos com o recebimento dos questionários dos CirurgiõesDentistas da cidade de Piracicaba-SP, observou-se que o Cirurgião-Dentista geralmente não participa de cursos, palestras e/ou aulas sobre PPR (57\%), prefere consultar outros Cirurgiões-Dentistas quanto à possibilidade de erros (55\%) e somente obteve informações sobre esta disciplina na Graduação (84\%). Porém, alega que há necessidade de cursos de atualização na área de PPR (70\%).

Destes dados, pode-se inferir que o CirurgiãoDentista, na sua maioria, considera que a disciplina de PPR, bem como todas as suas extensões são estáticas, pois mesmo afirmando que somente recebeu tais conhecimentos durante a graduação, a maioria não participou de cursos e ou palestras a respeito. Além dessa situação, é necessário que mais estudos longitudinais e transversais sejam efetuados visando detectar e apontar causas freqüentes de insucesso ${ }^{10,13}$ como o estudo de $\mathrm{Da}$ Silva, et al. ${ }^{7}$ que constatou que a principal causa de insucesso no tratamento com PPR's, juntamente com a cárie dental, é a perda de dentes pilares por periodontopatias.

A alta freqüência com que os cirurgiões dentistas alegam consultar outro profissional em vez de consultar livros e ou revistas especializadas ao encontrar problemas nas atividades práticas, o que ocorre na maioria das vezes informalmente, ou seja, por telefone, ou pessoalmente, sem, contudo, a existência de qualquer papel escrito (Parecer) que permita um respaldo por parte do Cirurgião-Dentista consulente, também é fator preocupante.

Não obstante a inexistência de documentos devido a informalidade das consultas, pode-se, por meio de provas, comprovar tal participação ${ }^{20}$ e o CirurgiãoDentista que emitiu uma segunda opinião poderá também ser responsabilizado pelo ato cometido e/ou tratamento realizado ${ }^{19}$. Este entendimento está de acordo com o Código de Ética Odontológico, artigo 34, parágrafo $\mathrm{IV}^{3}$.

Deve-se destacar que muitos cirurgiões-dentistas alegaram, quando da recepção do questionário, que não faziam PPR, pois estas davam muitos problemas. A falta de um estudo mais aprofundado sobre o tema (instalação de PPR) durante a graduação e a pós-graduação propicia a realização de serviços de baixa qualidade e, em contra partida, aumento de processos judiciais contra o Cirurgião-Dentista, desvirtuando uma área promissora e fazendo com que se deixe de acreditar na PPR, aparelho protético que ainda será utilizado por muitos e muitos anos. Tal pensamento encontra respaldo na literatura ${ }^{15}$. Faz-se necessário implementar e reestruturar o ensino de PPR aumentando a carga horária prática e fomentando uma melhor integração entre a teoria e a prática, se possível com reuniões (docentes e discentes) para discussão em conjunto de casos reais. Tal fato também é consenso entre os pesquisadores ${ }^{1,14}$. Também deverá o CirurgiãoDentista buscar cursos de aprimoramento, de extensão, de educação continuada, que lhes permitam a atualização necessária.

Nas associações de questões realizadas, pôde- 
Francesquini Jr L, et al. Conhecimento do cirurgião-dentista referente à avaliação de próteses parciais removíveis.

se observar uma melhor performance entre os indivíduos que haviam feito curso de pós-graduação (destaca-se que não se especificou uma única área das especialidades existentes).

Verificou-se, ainda, que o Cirurgião-Dentista desconhece a redação do parecer do Conselho Federal da Educação (90\%), do Código de Ética Odontológico (61\%) e da Resolução 209/97 (93\%). Esta resolução, hoje em vigor, é a 63/2005, que sofreu poucas alterações nesta área questionada.

Tais dados denotam a deficiência no conhecimento dos limites de atuação de cada profissional da Odontologia (Auxiliar de Consultório Dentário, Técnico em Higiene Dental, Técnico em Prótese Dentária, Auxiliar de Prótese Dentária, entre outros) Tais limites, encontram-se expressos nas legislações acima apontadas e encontram respaldo em trabalhos relatados ${ }^{18}$.

Como já se mostrou evidente, a responsabilidade pelo diagnóstico, desenho, planejamento e instalação da PPR, compete exclusivamente ao CirurgiãoDentista. Estas fases (preparo e planejamento, entre outras), na verdade, constituem-se em direito fundamental do Cirurgião-Dentista, previsto no Código de ética Odontológica ${ }^{17,21,22}$.

De uma forma em geral, o cirurgião-dentista participante afirmou verificar, quando da instalação da PPR, a retenção (85\%) e a função mastigatória $(91 \%)$. Porém, eles não observam a estabilidade $(61 \%)$, a reciprocidade $(85 \%)$, a fixação $(84 \%)$, a oclusão (53\%), a fonética $(77 \%)$ e a estética $(60 \%)$. Como se pode verificar ${ }^{6,13,16}$, tais características e funções são requisitos fundamentais de uma boa PPR e o não restabelecimento de uma delas acarretará sérios danos à integridade física ${ }^{10} \mathrm{e}$ psíquica do paciente ${ }^{2,6}$. Há que ser enfatizada a relevância desta avaliação fonética nos momentos pré e pós instalação do aparelho protético, atribuição dada ao cirurgião-dentista pela legislação vigente ${ }^{5}$.

Quando se avaliou o conhecimento do CirurgiãoDentista a respeito da retenção, verificou-se que $55 \%$ responderam corretamente, o mesmo ocorrendo com a estabilidade $(73 \%)$, idem para reciprocidade e braço de oposição (71\%), assentamento de PPR (67\%), estética (78\%), fonética $(67 \%)$, função mastigatória $(65 \%)$. Já no item reciprocidade, $56 \%$ não responderam corretamente.

Solicitou-se, ainda, aos Cirurgiões-Dentistas que descrevessem como avaliaram as funções estética, fonética e mastigatória. Obteve-se uma série de respostas, porém sem nenhuma ordem, roteiro ou padrão, o que demonstra a falta de utilização de livros e ou revistas especializadas, falta de ensino prático mais direcionado ${ }^{16}$, que pode acarretar danos físicos e sociais ao paciente ${ }^{2}$.

Quando questionou-se o Cirurgião-Dentista quanto a considerar-se apto a avaliar PPRs instaladas, verificou-se que $59 \%$ sentiam-se capazes para tal, porém, $41 \%$ se declaram inaptos.

Ao se questionar o Cirurgião-Dentista sobre a sua capacidade de avaliar o grau de satisfação dos indivíduos no tocante às PPRs, verificou-se que, embora $60 \%$ afirmem-se capazes, $40 \%$ se declararam inaptos.

Deve-se destacar que o Cirurgião-Dentista tem por obrigação avaliar a PPR instalada, bem como o grau de satisfação do indivíduo, pois, de acordo com o CPDC, caberá a ele provar que a aparatologia protética em questão encontra-se dentro de um padrão mínimo aceitável (inversão do ônus da prova) independentemente do fator individualidade ${ }^{9,20}$. Realmente, o Código de Proteção e Defesa do Consumidor estabelece tal obrigação, conforme definiu Vanrell|24.

O mesmo deveria ocorrer em empresas odontológicas, pois cabe a elas, segundo o Código de Ética Odontológica, fazer funcionar auditores (avaliadores) de procedimentos realizados pelos Cirurgiões-Dentistas associados e/ou conveniados. A existência de um protocolo evitaria que uma determinada PPR fosse aceita por um auditor e negada por outro.

Questionou-se o Cirurgião-Dentista a respeito de sua atitude no caso de um paciente não estar satisfeito com a PPR. Verificou-se que $46 \%$ deles fariam nova PPR sem custo ao indivíduo, 35\% fariam outra, porém cobrariam, e 19\% não fariam nova PPR, pois, segundo o item fornecido na questão, o indivíduo teria acompanhado todas as etapas e dado consentimento por escrito.

Outra vez denota-se que o Cirurgião-Dentista entrevistado desconhece os aspectos legais, pois somente $46 \%$ agiriam de forma correta, e em acordo com o Código de Proteção e Defesa do Consumidor (CPDC), ou seja, o Cirurgião-Dentista deve repetir o serviço, sem ônus ao indivíduo, mesmo que a insatisfação deste refira-se somente à cor dos dentes artificiais ${ }^{\text {? }}$.

A retirada de uma PPR já instalada da boca de um indivíduo, ou mesmo a recusa da instalação por falta 
Francesquini Jr L, et al. Conhecimento do cirurgião-dentista referente à avaliação de próteses parciais removíveis.

de pagamento dos honorários, são atitudes proibidas pelo CPDC. Desta forma, $44 \%$ dos CirurgiõesDentistas pesquisados estariam realizando um ato punível por este código.

Destaca-se, também, que o indivíduo pode, nesta hipótese, pleitear dano moral, uma vez que pode ter se sentido lesado ${ }^{20}$.

Questionou-se, também, a quem pertence o prontuário e verificou-se que $47 \%$ afirmaram que o mesmo pertence ao Cirurgião-Dentista, o que não é correto. A exigência de prontuários completos não é recente, e é indispensável nas demandas judiciais, quer seja para se previnir, quer seja para se documentar, quer seja para cobrar honorários não $\operatorname{pagos}^{1,12,23}$

\section{Conclusões}

De acordo com os resultados obtidos e as análises realizadas, é lícito concluir que: a) a maioria dos Cirurgiões-Dentistas da cidade de PiracicabaSP possuem conhecimentos precários necessários para o estabelecimento de um bom planejamento, confecção, bem como, uma correta avaliação das PPRs instaladas e proservação das mesmas, tornando-se imperativa a necessidade de cursos de educação continuada (extensão, atualização, palestras, entre outras) sobre a PPR, abrangendose, inclusive, a área de responsabilidade civil do Cirurgião-Dentista e demais auxiliares; b) a resolução 63/05 deixa claro que o cirurgiãodentista é o direto responsável por todos os passos do tratamento odontológico realizado por meio de próteses parciais removíveis, visto que este é o coordenador da equipe de trabalho com qual interage diretamente, visando o resultado final de qualquer tipo de tratamento realizado em seu consultório.

Francesquini Jr L, Rizatti-Barbosa CM, Ambrosano GMB, Darugue Jr E, Fernandes MM, Santos LSM. Conhecimento do cirurgião-dentista referente à avaliação de próteses parciais removíveis e à responsabilidade nos passos de sua confec ção. Saúde, Ética \& Justiça. 2009;14(1):9-16

Aвstract: Few manuscripts related to the dentist's knowledge about partial removable dentures and the responsibility related to their quality and installation are found in the national literature. For this reason, the present paper aimed at researching this subject among the dentists from the city of Piracicaba-SP and also doing a review on the responsibility of the other professionals involved in the denture manufacturing. Qui Square statistical analysis showed as a conclusion low levels of academic knowledge about the subject related to planning, installing, and evaluating standards for removable partial prosthesis among these professionals. The law about damage liability in dentistry states that the dentist is the only responsible professional for all the manufacturing steps of the denture, and these professionals are not aware of these facts.

KEYWORDS: Forensic dentistry. Damage liability. Removable.

\section{ReferênCIAS}

1. Altafin HC. Modelos de contratos de prestação de serviços odontológicos - aspectos éticos e legais [dissertação]. Piracicaba: Faculdade de Odontologia de Piracicaba, UNICAMP; 2003

2. Asckar EM, Tomita NE, Vilela SM, et al. Uso de prótese e grau de satisfação com a condição bucal no cotidiano de trabalhadores de Bragança Paulista/SP - Brasil. Odontologia USF. 2000;18(1):11-9.

3. Brasil. Conselho Federal de Odontologia. Código de Ética Odontológico [citado em 12 maio 2009]. Disponível em: http://www.cfo.org.br/legislacao/ default.cfm
4. Brasil. Lei Estadual 10.241 de 17 de março de 1999. Dispõe dos direitos dos usuários dos serviços e das ações de saúde no Estado e dá outras providências [citado em 12 maio 2009]. Disponível em URL: http:// www.imaginologia.com.br/dow/direitos-deveres/ Direitos-do-Paciente-Lei-Estado-de-Sao-Paulo.pdf.

5. Brasil. Lei Federal 5.081 de 24 de agosto de 1966. Regulamenta o exercício da profissão odontológica [citado em 30 jun. 2009]. Disponível em: http://www. cfo.org.br/legislação.

6. Castro Júnior OV, Hvanov ZV, Frigerio MLMA. Avaliação estética da montagem de seis dentes superiores anteriores em prótese total. Pesq Odont Bras. 2000;14(2):177-82. 
Francesquini Jr L, et al. Conhecimento do cirurgião-dentista referente à avaliação de próteses parciais removíveis.

7. Clavielli ITP. Natureza da obrigação assumida pelo Cirugião-Dentista no contrato de locação de serviços odontológicos. Rev APCD. 1996;50(4):315-8.

8. Da Silva PMB, Porto VC, Bonachella WC Aspectos periodontais em pacientes usuários de próteses parciais removíveis. Rev Odonto Ciênc. 2008;23(2):297-301.

9. Di Fiori SR. Atlas de prótese parcial removível. 4a ed São Paulo: Pancast Editorial; 1995.

10. Di Fiori SR . Prótese parcial removível: fundamentos bioprotéticos. São Paulo: Ed. Pancast; 1989.

11. França BHS. Documentação clínica do paciente: guardar por quê?. Rev Clín Ortodont Dental Press (Maringá). 2007;6(5):48-9.

12. Frank RP, Brudvik JS, Leroux B, et al. Relationship between the standarts of removable partial denture construction, clinical acceptability, and patient satisfaction. J Prost Dent. 2000;5(83):521-7.

13. Johnson DL, Stratton RJ. Fundamentos de prótese removível. São Paulo: Quintessence; 1988.

14. Kliemann C, Oliveira W. Manual de prótese parcia removível. São Paulo: Ed. Santos; 1999.

15. Loza Fernandez D. Identification de factores críticos em el diseño de la prótesis parcial removible atraves de la evaluacion de um programa de capacitacion aplicado a docentes de la Facultad de Estomatologia de la Universidad Peruana Cayetano Heredia [dissertação]. Lima: Universidad Peruana Cayetano Heredia; 1999.

16. Navarro H. Preparo de boca: importância na reabilitação com prótese parcial removível. RPG. 1996;3(4):314.

17. Paulino SM, Souza Filho CB, Cintra LF, et al. Próteses parciais removíveis de extremidade livre - critérios para o planejamento. Rev CRO-MG. 2001;7(3):22-31.

18. Pérez Leboreiro MT. Variación en el diseño de la prótesis parcial removible por diferentes laboratórios dentales. Rev ADM. 2001;58(2):74-9.

19. Phillips PT. The princelessingredients of ourprofession, life-span and causes for loss of serviceability. J Am Dent Assoc. 1970;81:1335-401.

20. Rosa FB. Dentista $x$ indivíduo ortodôntico: levantamento de problemas jurídicos nas últimas três décadas. JBOJ Bras Ortod Ortop M. 1997;2(12):1427.

21. Russomano C. Novo código civil brasileiro. São Paulo: Ed. Escala; 2003.

22. Simonetti FAA. Responsabilidade civil do cirurgiãodentista. Rev da APCD. 1999;53(6):449-51.

23. Teche FV, Miranda MA, Motta MFJ, et al. Tratamento reabilitador em um indivíduo com bruxismo severo. JBC - J Bras Clin Odontol Int. 2003;7(40):292-4.

24. Vanrell JP. Odontologia legal \& antropologia forense. Rio de Janeiro: Ed Guanabara Koogan; 2002.

Artigo recebido em: 17/04/2009.

Aprovado em: 22/05/2009. 